\section{Musculoskeletal Injury Rates in Multiday Marathon Runners Performing Ten Consecutive Marathons on a Repeat Course} Katie Small ${ }^{1 *}$ and Nicola Relph ${ }^{2}$

\begin{abstract}
Objective: To describe musculoskeletal injury rates in recreational runners completing ten marathons over ten consecutive days to help event organisers plan future injury preventative advice and strategies.

Methods: An observational study involving 27 recreational runners (age $45.1 \pm 7.47 \mathrm{yrs}$, mass $74.5 \pm 12.39 \mathrm{~kg}$, years running $11.6 \pm$ $9.42 \mathrm{yrs}$, average weekly mileage $41.9 \pm 12.72$ miles). Main outcome measures included total and percentage of musculoskeletal injuries, timing of injury occurrence during 10-day event, and daily individual marathon times.

Results: Twenty-six runners sustained 108 injuries, averaging 4 injuries per runner $(90.13$ per $1000 \mathrm{hr}) .89 \%$ of injuries involved the lower extremity; $24.1 \%$ foot, $18.5 \%$ hip/buttock, $16.7 \%$ ankle and $16.7 \%$ lower leg. Common injuries were blisters (15.7\%), Achilles tendinitis $(11.1 \%)$, medial tibial stress syndrome (MTSS) $(10.2 \%)$, iliotibial band syndrome (ITBS) $(9.3 \%)$ and low back pain (LBP) (9.3\%). $64.3 \%$ of injuries were sustained to the left limb. Chi-squared analysis revealed more injuries in days 1-3 than days 4-6 ( $p=0.013)$ and days 7-10 $(p=0.001)$. Repeated measures ANOVA comparing Days 1-3, 4-6 and 7-10 showed a significant main effect $(p=0.039)$. Post hoc analysis revealed Days 1-3 were significantly quicker time than days $7-10$ ( $p=0.037$, difference of $0.276 \mathrm{hrs}$ ).

Conclusion: Blisters, Achilles tendinitis, MTSS and ITBS are the most common lower extremity injurie in multiday marathons runners performing a repeat course over 10 consecutive days. Runners entering these events should perform appropriate injury prevention programmes. Runners should also be more reserved at the beginning of multiday events to avoid high initial injury risk. However, further investigation of injury rates and risk factors using larger sample sizes is required.
\end{abstract}

\section{Keywords}

Musculoskeletal injury; Runners; Marathon

\section{Introduction}

Ultra-endurance events have grown rapidly in popularity in the past few decades [1,2], with 313 multiday and over 3000 ultraendurance events planned for the Worldwide 2017-18 race calendar. Events vary in nature, ranging from point-to-point continuous

*Corresponding author: Katie Small, Department of Medical \& Sport Sciences, University of Cumbria, Fusehill Street, Carlisle, Cumbria, CA1 2WF, UK, Tel: 01228 61373; Fax: 01228 616235; E-mail: katie.small@cumbria.ac.uk

Received: July 10, 2017 Accepted: August 08, 2017 Published: August 12, 2017 running (100-150 miles) in a specified time, or more recently multiday point-to-point ultra-marathon races. Multiday competitions, such as RacingThePlanet $\odot$ and the Trans Swiss Run $\odot$ typically last 6-7 days in duration and cover 150 miles in total. Previous studies have investigated multiday ultra-endurance events using various sports, including running, cycling and swimming [3-5], with the focus on effects to the immune function, skeletal muscle damage and nutritional elements linked to recovery [6]. However, despite the growth in interest of multiday ultra-endurance events, little data exist regarding injury rates to athletes. A greater awareness of injury epidemiology is the foundation for prevention strategies [7].

Few studies have investigated injury rates during multiday ultramarathon road race events. An early study by Hutson [8] observed 24 runners during a six-day track race, covering a total distance of $936 \mathrm{~km}$. It was reported that $>60 \%$ of runners experienced an injury, the majority of which were noted as 'mild' in nature. The authors also observed the preponderance of injuries to the lower extremity, primarily the knee and ankle, although exact incidence rates were not reported. Fallon et al. [9] studied 32 runners during a $1005 \mathrm{~km}$ multiday road race. The runners sustained 64 musculoskeletal injuries, with $72 \%$ of all runners obtaining a minimum of one injury during the event. The authors reported the knee (31.3\%) and ankle $(28.1 \%)$ as the most commonly injured body regions. Another study by Bishop and Fallon [10] followed 17 runners completing a six-day track race. The authors noted a musculoskeletal injury rate of $65 \%$, with injuries again most frequently sustained to the ankle (36\%) and knee $(22 \%)$. However, it is difficult to compare injury incidence rates between studies when injuries per $1000 \mathrm{~h}$ of running are not reported [11]. In a systematic review and meta-analysis into incidence of running related injuries per 1000 hours of running in different types of runners, only one study to date has recorded this [12]. Krabak et al. [13] recorded an incidence rate of 65 injuries/illnesses per 1000 hours running, and 3.86 injuries per runner. However, this five day staged $240 \mathrm{~km}$ event over desert/wilderness terrain was performed in several locations throughout the world and with a wide variance in location temperature $\left(10^{\circ} \mathrm{C}-48^{\circ} \mathrm{C}\right)$ and altitude $(-30-+4300 \mathrm{~m})$. Therefore, it is unknown whether injuries/illnesses were related to the unique and varying conditions and running routes, and/or the accumulation of multiday endurance running.

Previous research has either investigated races on a repeated athletics grass track-based course [10], which lacks external validity, or road [9] and wilderness terrain [13] over a set point-to-point long distance, which lacks between day repeatability and reliability of terrain, direction and surface camber. To our knowledge, no study has evaluated injuries in multiday endurance runners performing a repeat course, over consecutive days. Therefore, the aim of the present study was to record musculoskeletal injury rates; areas and type, in recreational runners completing 10 marathons over 10 consecutive days using the same racing route. Daily individual race times would also be recorded to observe the relationship between injuries and race times over the 10-day event. The information gained would help inform race organisers and future event participants of injury prevention strategies. 


\section{Methods}

This was an observational prospective cohort study completed during the 2015 and 2016 'Brathay 10 in 10 '. The 'Brathay 10 in 10 ' is a unique endurance event. It consists of running ten marathons over ten consecutive days (total: $422 \mathrm{~km}$ ), on the same course, running around Lake Windermere in the Lake District, England. All runners completed a $42.2 \mathrm{~km}$ marathon on each of the ten days. The course remained the same, performed anticlockwise on a road tarmac surface, with the race start time set at 10:30 am each day. Participants were recruited by the event organisers, through the Brathay Hall Trust, Ambleside, England. All participants were experienced endurance runners; training and competing endurance/ultra-endurance events on a regular basis. The authors met with all participants four months prior to the events in 2015 and 2016, whereby they introduced the runners to the study design and rationale, and asked them to participate. All participants enrolled in the study gave their voluntary, written informed consent for their medical and race information to be used for research purposes. The study protocol was ethically approved by the University of Cumbria Ethical Review Board.

Twenty-seven recreational runners entered the study (17 male, 10 female, age $45.1 \pm 7.47 \mathrm{yrs}$, mass $74.5 \pm 12.39 \mathrm{~kg}$, years running $11.6 \pm 9.42 \mathrm{yrs}$, average weekly mileage $67.4 \pm 20.5 \mathrm{miles})$. On commencing the event, all runners were approved as 'fit to compete', without significant injury, by an experienced sports therapist. The medical staff consisted of two practitioners: a Sports Therapist and Sport Rehabilitator. Both were experienced in the medical care of ultra-marathoners and management of running injuries. The medical staff collected data on musculoskeletal injuries from the runners a minimum of three times every 24 -hour race-day period. Injuries were defined as 'a specific musculoskeletal abnormality that the runner perceived to affect his/her performance' (Bishop and Fallon, 1999) and were assessed and confirmed by both musculoskeletal therapists. All injuries were recorded on a standardized injury audit form noting the diagnosis, site of the injury and timing of onset during the event. Any participant who was unable to start a stage of the event was considered removed from the competition. Finally, individual race times were recorded daily by an independent timing system (SPORT_ident).

During the daily marathons, participants could carry any food/ drink they required, however, they had pre-prepared feed stations at two mile intervals, with food/drink supplies. All participants could choose their type and amount of food/drink daily. Race conditions varied each day, although maximum and minimum temperatures were $16^{\circ} \mathrm{C}$ and $6^{\circ} \mathrm{C}$, respectively. Race altitude was $183.7 \mathrm{ft}$ at the start, with a maximum elevation of $456.0 \mathrm{ft}$ and total ascent over the marathon course of $1492.8 \mathrm{ft}$.

\section{Statistical Analysis}

The total number of injuries and injuries by location were calculated as frequencies, percentages and per $1000 \mathrm{hrs}$ of running. Average race times were calculated as means and standard deviations. All statistical analyses were completed in SPSS (Version 24, IBM Corporation, New York, USA). Pearson's Chi-Squared analysis was used to compare the frequency of injuries from Days 1-3, Day 4-6 and Days 7-10, with an alpha level set at $\mathrm{p} \leq 0.05$. The KolmogorovSmirnov test was used to examine normality of race time data, which was confirmed $(\mathrm{p}=0.200)$. The differences in race times between Days 1-3, Days 4-6 and Days 7-10 were analysed using a one-way repeated measures ANOVA again with significance accepted at $\mathrm{p} \leq 0.05$. The assumption of sphericity was violated (Mauchly's test $\mathrm{p}=0.012$ ) therefore the Greenhouse-Geisser correction was applied to the main effects analysis. Post-hoc pairwise comparisons were completed using a Bonferroni analysis with alpha level set at $\mathrm{p} \leq 0.05$.

\section{Results}

26 runners completed the event and all 10 consecutive marathons. One runner withdrew due to serious injury; diagnosed as a Grade II medial collateral knee ligament injury. The injury occurred during day 5 of the event, whereby the runner withdrew at $8 \mathrm{~km}$ into the marathon. Previous injury data concerning the runner was removed from statistical analysis.

\section{Injuries}

Twenty-five of the runners (95.16\%) sustained a total of 108 injuries, averaging 4 injuries per runner $(90.13$ per $1000 \mathrm{hr})$. Only one runner sustained no injuries, whilst the highest number of injuries recorded per runner was 10 . A total of $64.3 \%$ of injuries were sustained to the left limb.

$89 \%$ of injuries involved the lower extremity; $24.1 \%$ foot, $18.5 \%$ hip/buttock, $16.7 \%$ ankle and $16.7 \%$ lower leg. The remaining $11 \%$ of injuries were spinal/trunk. Common injuries were blisters (15.7\%; 14.18 per $1000 \mathrm{hr}$ ), Achilles tendinitis (11.1\%; 10.01 per $1000 \mathrm{hr}$ ), medial tibial stress syndrome (MTSS) (10.2\%; 9.18 per $1000 \mathrm{hr}$ ), iliotibial band syndrome (ITBS) $(9.3 \%$; 8.35 per $1000 \mathrm{hr})$ and low back pain (LBP) (9.3\%; 8.35 per $1000 \mathrm{hr})$.

\section{Injury incidence and race time}

Chi-squared analysis revealed more injuries in days 1-3 (54) than days 4-6 (31) ( $\mathrm{p}=0.013)$ and days 7-10 (23) $(\mathrm{p}=0.001)$. Repeated measures ANOVA comparing Days 1-3, 4-6 and 7-10 showed a significant main effect $(\mathrm{p}=0.039)$. Post hoc analysis revealed Days 1-3 were significantly quicker time than days $7-10(\mathrm{p}=0.037$, difference of $0.276 \mathrm{hrs}$ ) (Figure 1).

\section{Discussion}

Despite the increased popularity in multiday ultra-endurance events, there is little data regarding injury epidemiology. To our knowledge, this was the first study to report on musculoskeletal injury rates in ultra-endurance runners performing consecutive marathons on a repeat road-based course. In our study, $95.16 \%$ of runners sustained injuries, which is higher than reported in previous multi-day endurance running research $(56.5-84.8 \%$ [10,13-15]. This averaged at 4 injuries per runner, compared to $0.71-2.7$ injuries per runner in previous studies $[9,13]$. The overall injury rate was 90.13 per $1000 \mathrm{hr}$, which again is higher than that observed by Krabak et al. [13] in a five day off-road ultra-endurance study (65 per 1000 $\mathrm{hr})$. However, no other studies concerning ultra-endurance running events are available for comparison since they did not report the injury rate per 1000 hours, or total hours for all runners for it to be calculated retrospectively. This limitation has previously been highlighted by Jakobsen et al. [11] as it would help provide a more comparable measure of association. However, when considering individual marathon events, the rate observed in the current study is also, unsurprisingly, significantly higher (6.8-59 per 1000 hours [16]). This study involved the greatest number of consecutive marathons (10) in comparison to previous multiday endurance running event studies (4-8.5 days), or single marathon events, which may explain the high incidence rate observed. Furthermore, musculoskeletal injury rates may be lower in previous ultra-endurance running studies due to the off-road nature (trail or grass) as opposed to road running which 


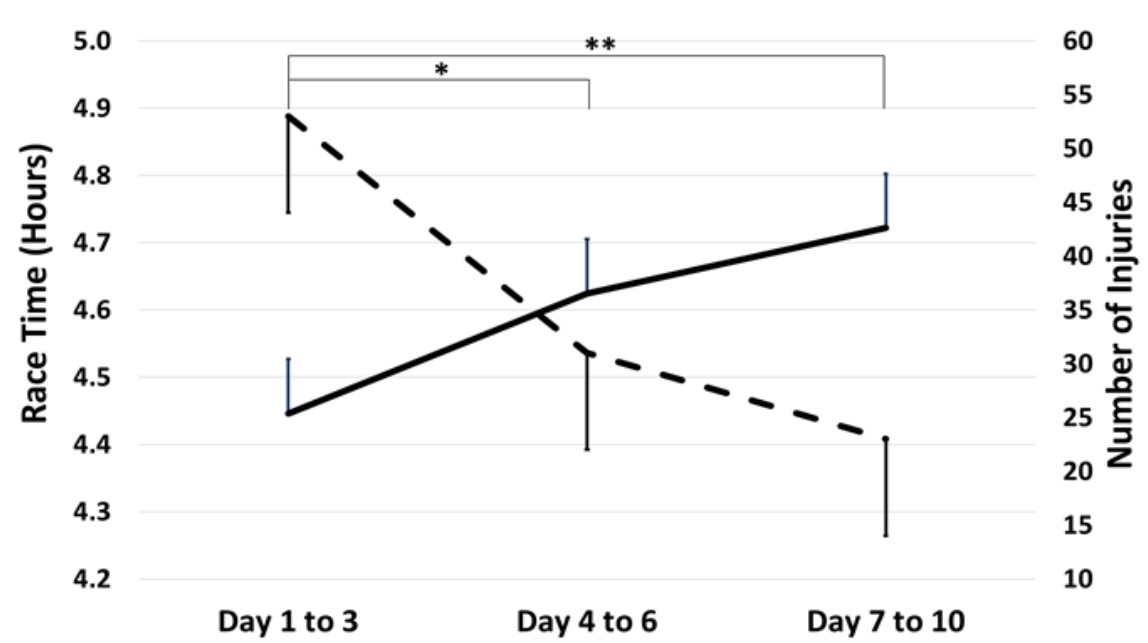

\section{-Race Time (Hours) - Number of Injuries}

Figure 1: Race Times (mean+SE) and Number of Injuries (sum-SE). *Sig. difference in injuries between days 1-3 and 4-6. ** Sig. difference in injuries and time between days $1-3$ and $7-10$.

is associated with increased chance for cumulative trauma [13].

Regarding musculoskeletal injuries sustained, blisters were the most commonly reported (15.7\%; 14.18 per $1000 \mathrm{hr})$. This is lower than reported by Scheer and Murray [15] and Krabak et al. [13] (26.1 and $55.58 \%$, respectively), although which is in line with single marathon running events (0.2-39) [17]. Risk factors associated with blisters include heat, moisture, increased running volume and illfitting footwear [17]. Runners in the current study were prone to changing footwear during the event. The increased variety, potentially including ill-fitting shoes, may have contributed to the high incidence rate observed, although this is only conjecture and warrants further investigation.

Achilles tendinitis was recorded as the second most common injury with an incidence rate of $11.1 \%$ (10.01 per $1000 \mathrm{hr})$. This is consistent with previous research by Hoffman and Fogard [18] (11.5\%), and other ultra-marathon studies where prevalence rates have been reported 2-18.5\% [16]. Excessive loading during physical activity is considered to be the main stimulus for the development of tendinopathies [19]. The high, repetitive loading generated in the gastrocnemius and soleus during running may predispose runners to the development of Achilles tendinitis [20]. However, despite ten consecutive marathons completed in the current investigation, the incidence rate of Achilles tendinitis wasn't as high as reported by other research from Lopes et al. [16] involving lower volume events. This may be explained by the different types of running surface in the events studied. It has been reported that softer surfaces, such as trail or sand, demand higher propulsive forces on push-off [21], compared to road as was the running surface in the current investigation. Consequently, runners may adopt a greater forefoot running technique which decreases landing time and increases running velocity, but whilst creating a higher load on the Achilles tendon, leading to more degeneration [21]. However, there are little high quality prospective cohort studies which compare Achilles tendon loading on different terrains to confirm these findings.

In a systematic review by Lopes et al. [16], Medial tibial stress syndrome (MTSS) was reported to account for $7.8-11.1 \%$ of total injuries in ultra-marathon events which is supported by the current observed incidence rate of $10.2 \%$ (9.18 per $1000 \mathrm{hr}$ ). MTSS refers to exercise-related pain at the posteromedial border of the mid-distal tibia [22]. The high frequency rate of MTSS has been suggested to be related to insufficient capacity of bone remodelling constituted by repetitive and persistent stress on the tibia by muscular contraction and high ground reaction forces during running [23]. This may be exacerbated for the runners during the study due to inadequate healing time when running over 10 consecutive days. Other factors such as predisposing biomechanical issues, hyperpronation, greater knee valgus or different types of running have also been associated with development of MTSS [24]. However, cause-effect relationships are yet to be determined [16].

Iliotibial band syndrome (ITBS) has been reported as the most common cause of lateral knee pain in runners, with an incidence rate of up to $12 \%$ [25]. A similar incidence rate was found in the present study of $9.3 \%$ ( 8.35 per $1000 \mathrm{hr}$ ), although which is higher than that reported by Fallon [14] (4.7\%) in ultra-marathon runners. The ITB is a lateral stabiliser of the knee joint [26]. Straus et al. [27] proposed an impingement zone at $30^{\circ}$ knee flexion, and that running uphill and downhill, which is common in ultra-marathons, may lead to higher fractional time in this zone. The marathon course used in the current study involved a total ascent of $1492.8 \mathrm{ft}$, which may therefore explain the higher reported incidence rate of ITBS.

Whilst lower limb injuries constituted $89 \%$ of total injuries, the remaining $11 \%$ of injuries were to the spine/trunk [28]. Specifically, low back pain (LBP) accounted for $9.3 \%(8.35$ per $1000 \mathrm{hr})$ of all injuries. This is greater than observed by Fallon [14] (3.1\%). Higher loading may be associated with running on a harder surface (tarmac road in the current study), whereby impact on foot-strike can be up to three times total body weight [29]. This may help explain the higher incidence of LBP recorded in the present study. However, further epidemiological, as well as biomechanical studies are required to substantiate these claims.

When excluding spinal injuries, $64.3 \%$ of injuries were sustained to the left limb. The finding of left predominance to injury is in 
agreement with previous studies during both ultra-marathons events [14] and long-term endurance running training [28]. However, in a study by Fallon and Bishop [10], there was an even distribution of injuries between left and right limb. Both this and the previous study by Fallon [14] were performed as ultra-endurance events over six days on a track course. However, in the latter study by Fallen and Bishop [10] the runners were instructed to change direction every 2-hours, as opposed to uni-directional running in the previous study by Fallon [14]. It has been hypothesized that road camber can lead to unequal load distribution on the legs [28]. This repetitive biomechanical alteration in gait pattern may have resulted in the increased incidence of injuries to the left leg. However, few studies discuss road camber in relation to injury incidence as an aetiological factor, and therefore further research is required to explore this area.

Krabak et al. [13] observed a cumulative effect for musculoskeletal injuries later in multiday endurance running. This was expected by the authors, who suggested that greater incidence of injuries would develop when running greater distances on sequential days and without standard rest/recovery time. Whilst this does indeed seem logical, current findings contradict this theory. Results from the investigation observed significantly more injuries in days 1-3 than days 4-6 and 7-10. This finding may be related to race times over the 10 days. There was a general pattern of increased race times over the 10-day event, with race times in days 1-3 significantly quicker than days 7-10. It could be postulated that, following a likely period of tapering prior to the start of the event, runners entered feeling rested and therefore began with a higher pacing strategy. However, increased pace has been associated with overuse injury in runners, including Achilles tendinitis as was prevalent in the current study, even if running volume remains the same [30]. This may be related to quicker muscle tension alterations which lead to increased predisposition to microtears as pace increases [31]. Consequently, and due to reduced function and/or increased pain associated with injury, runners may then have been forced to reduce their pace, thus reducing further injury susceptibility. However, it could also be considered that by the latter stages of the event runners had learnt techniques to treat their own injuries and therefore not presented or detailed the conditions to medical staff, thus lowering the end-stage reported injury incidence rates. This was observed by Krabak et al. [13] whereby runners selftreated for blisters towards the end of multiday endurance events.

\section{Limitations}

This study describes musculoskeletal injury rates during 10-day consecutive marathon running on the same course and is limited by its small sample size. Collecting and reviewing data over forthcoming years and events would provide a more accurate assessment of injury epidemiology in this demographic. Furthermore, the methods of data collection used did not allow for identification of injury risk factors such as demographic, anthropometric, health history and training history, which may be an area of future research exploration.

\section{Conclusion}

In summary, this study observed common musculoskeletal injuries in multiday ultra-endurance runners completing 10 marathons over 10 consecutive days, on the same road-based circular course. The vast proportion of injuries was in the lower extremity; the most common being blisters, achilles tendinitis, MTSS and ITBS. Athletes entering these events should engage in appropriate injury prevention programmes to target these injuries. The majority of injuries were sustained to the left limb; multiday marathon event organisers should consider alternating route direction to reduce injury risk, potentially the result of prolonged, altered gait biomechanics. There was an inverse relationship between injuries and race times, with most injuries sustained in days 1-3, and during faster individual race time days. Future runners should consider a slower, more gradual start to multi-day endurance events. However, further investigation of injury rates and both etiological and biomechanical risk factors using larger sample sizes is required to further inform this area of study.

\section{Acknowledgements}

The authors would like to thank the runners of the Brathay 10 in 10 to take part in the event and research study.

\section{References}

1. Hoffman MD (2010) Performance trends in 161-km ultramarathons. Int J Sports Med 31: 31-37.

2. Hoffman MD, Ong JC, Wang G (2010) Historical analysis of participation in $161 \mathrm{~km}$ ultramarathons in North America. Int J Hist Sport 27: 1877-1891.

3. Gleeson M, McDonald WA, Cripps AW, Pyne DB, Clancy RL, et al. (1995) The effect on immunity of long-term intensive training in elite swimmers. Clin Exp Immunol 102: 210-216.

4. McKune AJ, Smith LL, Semple SJ, Wadee AA (2005) Influence of ultraendurance exercise on immunoglobulin isotypes and subclasses. $\mathrm{Br} \mathrm{J}$ Sports Med 39: 665-670

5. Nieman DC (2009) Immune function responses to ultramarathon race competition. Medicina Sportiva 13:189-196.

6. Zaryski C, Smith DJ (2005) Training principles and issues for ultra-endurance athletes. Curr Sports Med Rep 4: 165-170.

7. van Mechelen W, Hlobil H, Kemper HC (1992) Incidence, severity, aetiology and prevention of sports injuries. A review of concepts. Sports Med 14: 82-99.

8. Hutson MA (1984) Medical implications of ultra-marathon running observations on a six day track race. Br J Sports Med 18: 44-45.

9. Fallon KE, Sivyer G, Sivyer K, Dare A (1999) The biochemistry of runners in a $1600 \mathrm{~km}$ ultramarathon. Br J Sports Med 33: 264-269.

10. Bishop GW, Fallon KE (1999) Musculoskeletal injuries in a six-day track race: ultramarathoner's ankle. Clin J Sport Med 9: 216-220.

11. Jakobsen BW, Krøner K, Schmidt SA, Kjeldsen A (1994) Prevention of injuries in long-distance runners. Knee Surg Sports Traumatol Arthrosc 2: 245-249.

12. VidebÃ running-related injuries per $1000 \mathrm{~h}$ of running in different types of runners: a systematic review and meta-analysis. Sports Med 45: 1017-1026.

13. Krabak BJ, Waite B, Schiff MA (2011) Study of injury and illness rates in multiday ultramarathon runners. Med Sci Sports Exerc 43: 2314-2320.

14. Fallon KE (1996) Musculoskeletal injuries in the ultramarathon: the 1990 Westfield Sydney to Melbourne run. Br J Sports Med 30: 319-323.

15. Scheer BV, Murray A (2011) Al Andalus Ultra Trail: an observation of medical interventions during a 219-km, 5-day ultramarathon stage race. Clin J Sport Med 21: 444-446.

16. Lopes AD, Hespanhol Júnior LC, Yeung SS, Costa LO (2012) What are the main running-related musculoskeletal injuries? A Systematic Review. Sports Med 42: 891-905.

17. Mailler EA, Adams BB (2004) The wear and tear of 26.2: dermatological injuries reported on marathon day. Br J Sports Med 38: 498-501.

18. Hoffman MD, Fogard K (2011) Factors related to successful completion of a 161-km ultramarathon. Int J Sports Physiol Perform 6: 25-37.

19. Selvanetti A, Cipolla M, Puddu G (1997) Overuse tendon injuries: basic science and classification. Op Tech Sports Med 5(3), 110-117.

20. Arndt AN, Komi PV, Brüggemann GP, Lukkariniemi J (1998) Individual muscle contributions to the in vivo achilles tendon force. Clin Biomech (Bristol, Avon) 13: $532-541$. 
Citation: Small K, Relph N (2017) Musculoskeletal Injury Rates in Multiday Marathon Runners Performing Ten Consecutive Marathons on a Repeat Course. $J$ Athl Enhanc 6:5.

21. Knobloch K, Yoon U, Vogt PM (2008) Acute and overuse injuries correlated to hours of training in master running athletes. Foot Ankle Int 29: 671-676.

22. Batt ME (1995) Shin splints--a review of terminology. Clin J Sport Med 5 53-57.

23. Craig DI (2008) Medial tibial stress syndrome: evidence-based prevention. J Athl Train 43: 316-318.

24. Wen DY, Puffer JC, Schmalzried TP (1998) Injuries in runners: a prospective study of alignment. Clin J Sport Med 8: 187-194.

25. Taunton JE, Ryan MB, Clement DB, McKenzie DC, Lloyd-Smith DR, et al. (2002) A retrospective case-control analysis of 2002 running injuries. $\mathrm{Br}$ Sports Med 36: 95-101.

26. Ellis R, Hing W, Reid D (2007) Iliotibial band friction syndrome--a systematic review. Man Ther 12: 200-208.
27. Strauss EJ, Kim S, Calcei JG, Park D (2011) Iliotibial band syndrome: evaluation and management. J Am Acad Orthop Surg 19: 728-736.

28. Bovens AM, Janssen GM, Vermeer HG, Hoeberigs JH, Janssen MP, et al. (1989) Occurrence of running injuries in adults following a supervised training program. Int J Sports Med 10 Suppl 3: S186-190.

29. Lieberman DE, Venkadesan M, Werbel WA, Daoud AI, D'Andrea S, et al. (2010) Foot strike patterns and collision forces in habitually barefoot versus shod runners. Nature 463: 531-535.

30. McCrory JL, Martin DF, Lowery RB, Cannon DW, Curl WW, et al. (1999) Etiologic factors associated with Achilles tendinitis in runners. Med Sci Sports Exerc 31: 1374-1381

31. Nielsen RO, Nohr EA, Rasmussen S, Sørensen H (2013) Classifying runningrelated injuries based upon etiology, with emphasis on volume and pace. Int $\mathrm{J}$ Sports Phys Ther 8: 172-179.

\section{Author Affiliations}

${ }^{1}$ Department of Medical and Sport Sciences, University of Cumbria, UK ${ }^{2}$ Department of Sport and Physical Activity, Edgehill University, UK

Submit your next manuscript and get advantages of SciTechnol submissions

* 80 Journals

* 21 Day rapid review process

* 3000 Editorial team

* 5 Million readers

* More than 5000 facebook"

* Quality and quick review processing through Editorial Manager System

Submit your next manuscript at • www.scitechnol.com/submission 